Rechtsmedizin 2012 $\cdot 22: 222-222$

DOI 10.1007/s00194-012-0828-7

๑) Springer-Verlag 2012
S. Fieseler · S.N. Kunz • O. Peschel · B. Zinka

Institut für Rechtsmedizin, Ludwig-Maximilians-Universität, München

\section{Erratum zu: Suizid mithilfe einer Armbrust}

In dem Beitrag Der besondere Fall im Bild „Suizid mithilfe einer Armbrust“ sind die abgedruckten Computertomographie(CT)-Bilder (Abb. 3a,b), deren Quelle und die forensisch-radiologischen Befunde nicht ordnungsgemäß wiedergegeben worden. Wir bitten daher, zukünftig die unten abgedruckten Bilder (- Abb. 3a-c) und Bildlegenden zu verwenden. Die Bilder wurden von der AG „pm CT“ (verantwortlich: PD Dr. med. S.M. Kirchhoff, Radiologie und Dr. med. F.T. Fischer, Rechtsmedizin) zur Verfügung gestellt, befundet und beurteilt.

Die Redaktion

\section{Korrespondenzadresse}

\section{PD Dr. S.M. Kirchhoff}

Institut für Klinische Radiologie

Klinikum der Universität München

Campus Innenstadt Ludwig-Maximilians-

Universität München

Nussbaumstr. 20

80336 München

sonja.kirchhoff@med.uni-muenchen.de
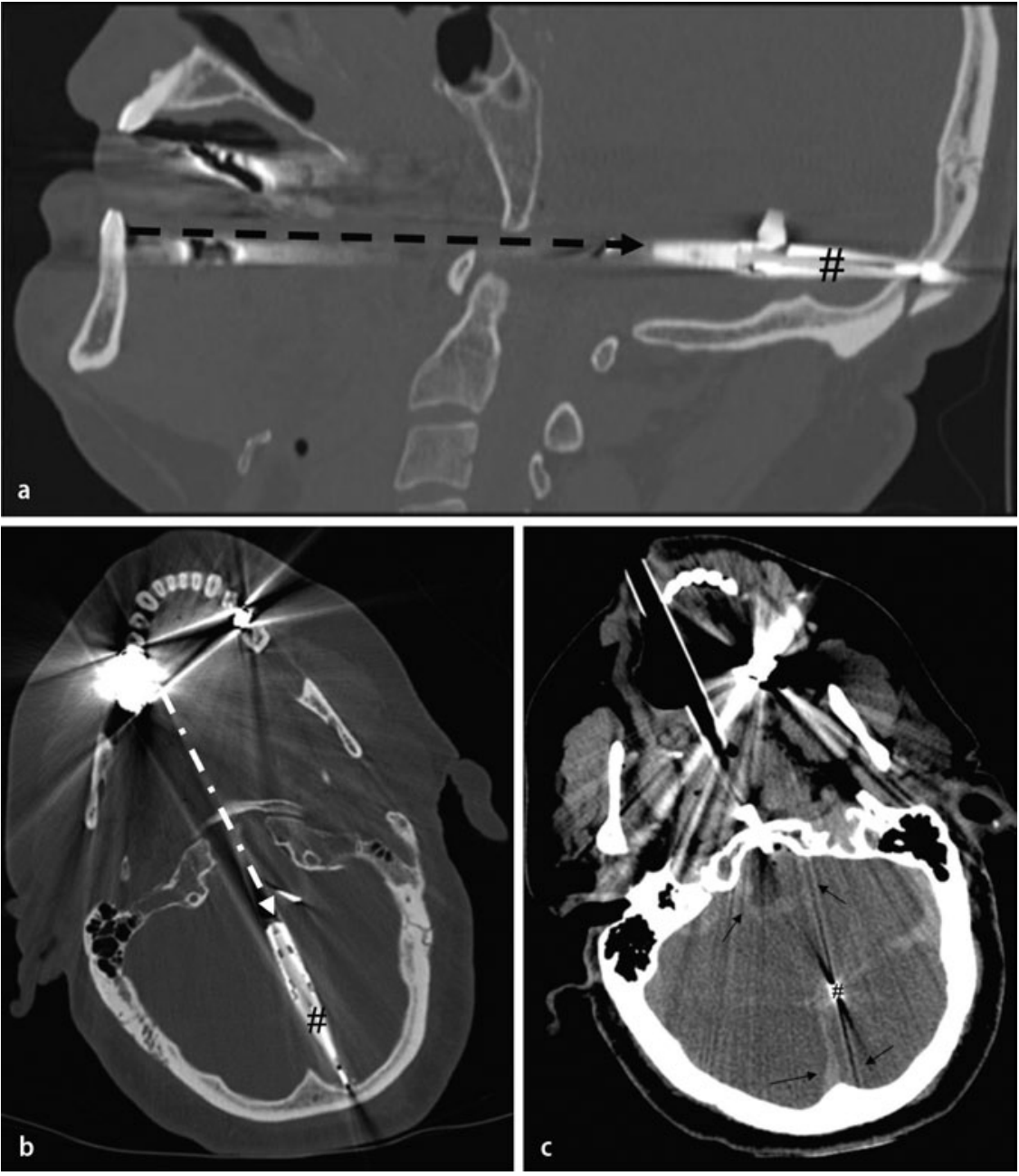

Abb. 3 A Postmortale CT-Untersuchung des Schädels. a Sagittale Bildrekonstruktion in Knochentechnik mit partieller Darstellung des Schusskanals (schwarzer Pfeil) und Abbildung der Pfeilspitze (Doppelkreuz), die die Schädelkalotte okzipital durchdringt und eine Knochenschuppe (Asterisk) absprengt. Die Form des knöchernen Defekts unterhalb der Knochenschuppe hätte unabhängig vom hier noch liegenden Pfeil Hinweischarakter für eine Bestimmung der Schussrichtung. b Korrespondierende transversale Bildrekonstruktion in Knochentechnik mit partieller Darstellung des Schusskanals (weißer Pfeil) und Abbildung der Pfeilspitze (Doppelkreuz). c Transversale Bildrekonstruktion in Weichteiltechnik. Hier deuten die schwarzen kleinen Pfeile auf eine Blutung in die basalen Zisternen, die ggf. als Vitalitätszeichen zu diskutieren und histomorphologisch ist. (Das Doppelkreuz demonstriert die Abbildung der Pfeilspitze. (Institut für klinische Radiologie der LMU München, mit freundl. Genehmigung) 